\title{
Improved accuracy using a modified registration method of ROSA in deep brain stimulation surgery
}

\author{
*Feng Xu, MD, Hai Jin, MD, Xingwang Yang, MD, Xiao Sun, MD, Yu Wang, MD, Mengting Xu, MD, \\ and Yingqun Tao, MD
}

Department of Neurosurgery, General Hospital of Shenyang Military Area Command, Shenyang, Liaoning, People's Republic of China

OBJECTIVE The aim of this study was to determine whether a modified registration method could reduce registration error and postoperative electrode vector error and to analyze the method's clinical significance in deep brain stimulation (DBS) surgery.

METHODS The first part of the study involved a skull model, in which three registration methods were tested using the ROSA (robotic stereotactic assistance) system. In the second part, four registration methods were clinically tested in patients undergoing DBS surgery using the ROSA system. Thirty-three patients ( 65 sides, group I) underwent the conventional registration method $2 \mathrm{E}$, and registration errors were recorded. Thirty-eight patients ( 75 sides, group II) underwent four types of modified registration methods including 2A, 2B, 2C, and 2D. Registration and electrode vector errors, intraoperative electrophysiological signal length (IESL), and DBS power-on voltage were recorded. The primary measure of efficacy was the change in the Unified Parkinson's Disease Rating Scale (UPDRS) and UPDRS Part III scores from baseline to 10 weeks after surgery.

RESULTS In the skull model, the registration error (mean $\pm S D$ ) was $0.56 \pm 0.11 \mathrm{~mm}$ for method $1 \mathrm{~A}, 0.35 \pm 0.11 \mathrm{~mm}$ for method 1B (vs. 1A, p < 0.001), and $0.90 \pm 0.15 \mathrm{~mm}$ for method $1 \mathrm{C}$ (vs. 1A, $p<0.001$ ). In the clinical study, method $2 \mathrm{C}$ was selected for DBS surgery in group II since it had the smallest registration error among the four methods tested. The registration error was $0.62 \pm 0.22 \mathrm{~mm}$ (mean $\pm \mathrm{SD}$ ) for group I and $0.27 \pm 0.07 \mathrm{~mm}$ for group II $(p<0.001)$. Postoperative electrode vector error was $0.97 \pm 0.31 \mathrm{~mm}$ for group I and $0.65 \pm 0.23 \mathrm{~mm}$ for group II $(p<0.001)$. There was a positive correlation between registration error and electrode vector error in both groups (group I: $r=0.69, p<0.001$; group II: $r=0.71, p<0.001)$. The mean IESL was $5.0 \pm 0.9 \mathrm{~mm}$ in group I and $5.8 \pm 0.7 \mathrm{~mm}$ in group II ( $<0.001)$. The mean DBS power-on voltage was $1.63 \pm 0.44 \mathrm{~V}$ in group I and $1.48 \pm 0.38 \mathrm{~V}$ in group II $(p=0.027)$. In the UPDRS score, group I showed $50 \% \pm 16 \%$ improvement and group II showed $52 \% \pm 18 \%$ improvement $(p=0.724)$; there was no statistically significant difference in improvement on the UPDRS.

CONCLUSIONS In DBS surgery assisted by the ROSA system, registration error and electrode vector error showed a positive correlation. The modified registration method could reduce the registration error and electrode vector error, but the long-term effects need to be further observed and evaluated.

https://thejns.org/doi/abs/10.3171/2018.4.FOCUS1815

KEYWORDS deep brain stimulation; ROSA; modified registration; registration error; electrode vector error

$\mathrm{D}$ EEP brain stimulation (DBS) is an established treatment for severe movement disorders, leading to a significant reduction in motor deficits in the majority of patients. ${ }^{17}$ However, despite its often striking clinical benefits, DBS remains a complex and poorly standardized therapy requiring a high level of clinical expertise and in- volving a multistep procedure during which treatment failures can occur due to misplaced stimulating electrodes. ${ }^{5}$ The ROSA (robotic stereotactic assistance) system is a new device for DBS surgery. In 2017, Vadera et al. reported on the first DBS implantation procedure performed using a robot (ROSA robotic device) approved by the Food and Drug

ABBREVIATIONS DBS = deep brain stimulation; IESL = intraoperative electrophysiological signal length; STN = subthalamic nucleus; UPDRS = Unified Parkinson's Disease Rating Scale; UPDRS-III = UPDRS Part III.

SUBMITTED January 4, 2018. ACCEPTED April 11, 2018.

INCLUDE WHEN CITING DOI: 10.3171/2018.4.FOCUS1815.

${ }^{*}$ F.X. and H.J. contributed equally to this study. 
Administration for use in the United States. ${ }^{16}$ We have been using ROSA for DBS surgery since 2016. ${ }^{20}$ The ROSA instructions recommended a conventional registration method of placing the tip of the registration probe in a position tangent to the groove of the bone screws. ${ }^{6,716}$ In practice, we found that shifting the probe tip slightly off the groove might improve registration accuracy. Herein, we conducted a study to investigate the accuracy of the ROSA device, first in a skull model, then in a clinical situation.

\section{Methods}

\section{The First Step: Skull Model Study}

We used bone screws as fiducial markers, 3 that were $10 \mathrm{~mm}$ long, 10 that were $15 \mathrm{~mm}$ long, and 3 that were 20 $\mathrm{mm}$ long (2023-VG, ALCIS Co.). We used the ROSA robotic system (MedTech) for the surgery. The skull model was created by the Baizhou Company. A total of 16 bone markers were randomly fixed on the skull model surface. Three-dimensional head CT (GE-Discovery-CT-750, USA) was performed at a room temperature of $24^{\circ} \mathrm{C}$. Scanning parameters were as follows: spiral scanning, 120 $\mathrm{KV}, 300 \mathrm{~mA}, 5-\mathrm{mm}$ slice thickness. The scan data were imported into the ROSA software system. We randomly selected 5 markers each time for the registration planning methods 1A, 1B, and 1C. As shown in Fig. 1, in registration method 1A, the line of the probe tip was set in the groove of the bone screw marker. In registration method $1 \mathrm{~B}$, the line of the probe tip was shifted $0.5 \mathrm{~mm}$ toward the tip of the bone marker. In registration method $1 \mathrm{C}$, the probe tip was shifted $0.5 \mathrm{~mm}$ away from the tail of the bone marker. Registration tests were conducted 15 times for each method. The data were analyzed using a t-test.

\section{The Second Step: Clinical Study}

The study was approved by the institutional review board and the ethics committee of the General Hospital of Shenyang Military Area Command. The study protocol followed the principles outlined in the Declaration of Helsinki. In our department, 71 patients underwent DBS surgery (140 sides) using the ROSA device between June 2016 and June 2017. Preoperative MRI (Siemens MAGNETOM Verio 3T Tim) scanning parameters were as follows: T2weighted imaging (TR $3000 \mathrm{sec}$, TE $413 \mathrm{sec}$, matrix $260 \times$ 256 , slices 88 , slice thickness $2.00 \mathrm{~mm}$, voxel size $1 \times 1 \times 2$ $\mathrm{mm}$ ) and T1-weighted imaging (TR $1900 \mathrm{sec}$, TE $2.91 \mathrm{sec}$, matrix $260 \times 256$, slices 88 , slice thickness $2.00 \mathrm{~mm}$, voxel size $1 \times 1 \times 2 \mathrm{~mm}$ ). The electrode (L-301, PINS Medical) was implanted in the subthalamic nucleus (STN). ${ }^{3,4}$ Post-
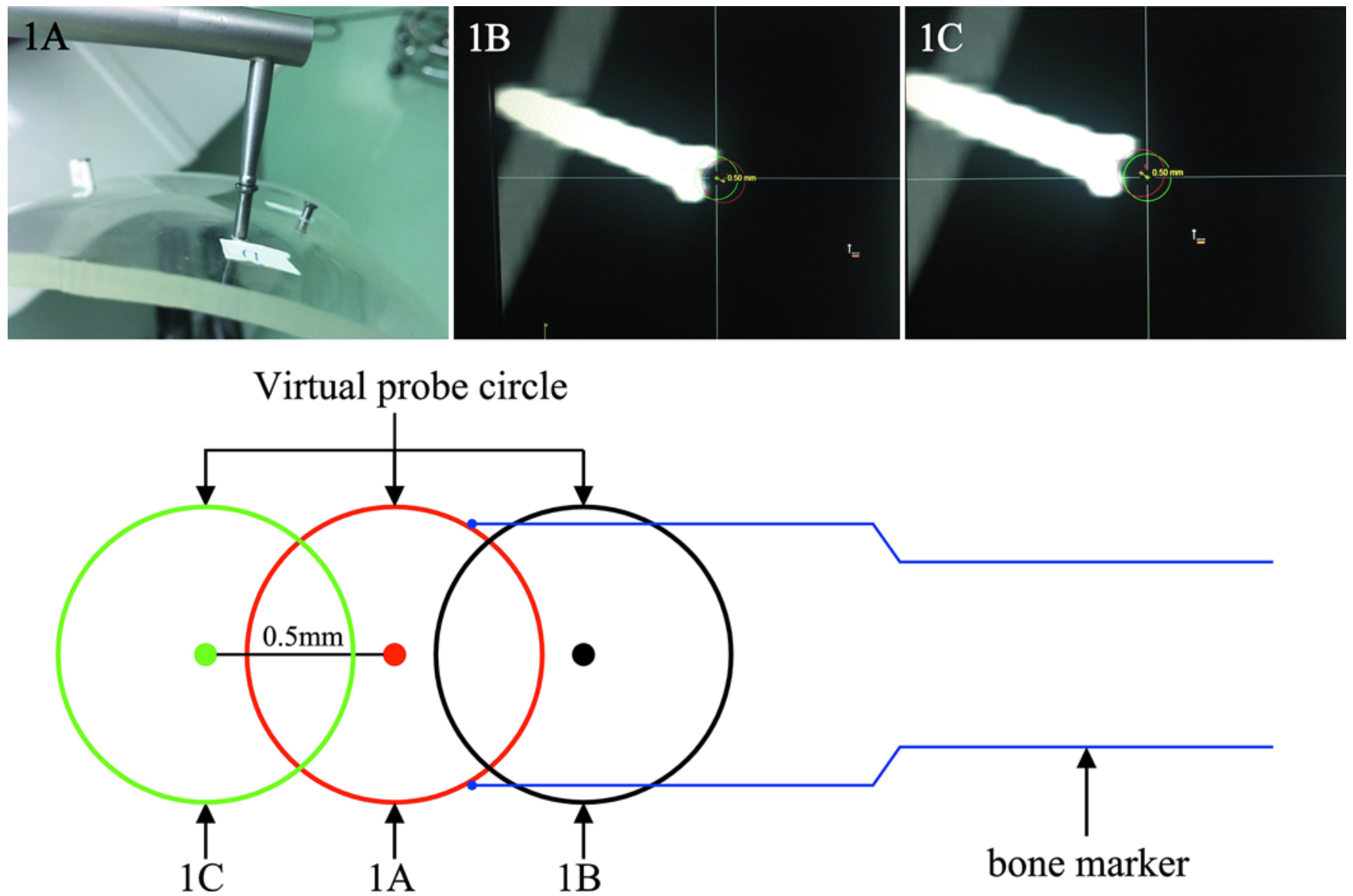

FIG. 1. Modified registration method in a skull model. In registration method $1 \mathrm{~A}$, the probe tip was set in the groove of the bone marker. In registration method $1 \mathrm{~B}$, the probe tip was shifted $0.5 \mathrm{~mm}$ into the tip of the bone marker. In registration method $1 \mathrm{C}$, the probe tip was shifted $0.5 \mathrm{~mm}$ away from the tail of the bone marker. 
operative CT (Discovery CT750, GE Healthcare) scanning parameters were as follows: spiral scanning, $100 \mathrm{KV}, 350$ $\mathrm{mA}, 5-\mathrm{mm}$ slice thickness. Three-dimensional CT data were imported into the ROSA software system to create an image fused with the preoperative MR image. The electrode vector error was defined as the distance from the electrode's implanted position to its preoperative target as calculated by the ROSA software.

The patients were divided into two groups, according to the different registration methods used. In group I, 33 patients (65 sides) underwent registration via the conventional method (method $2 \mathrm{E}$ ) required by ROSA for DBS surgery, and registration errors were recorded. ${ }^{16}$

In group II, 38 patients ( 75 sides) underwent registration via four modified methods including $2 \mathrm{~A}, 2 \mathrm{~B}, 2 \mathrm{C}$, and $2 \mathrm{D}$ (Fig. 2). For method 2A, the line of the probe tip was set in the groove of the bone marker. For method $2 \mathrm{~B}$, the probe tip was shifted $0.25 \mathrm{~mm}$ toward the tip of the bone marker. For method 2C, the probe tip was shifted $0.5 \mathrm{~mm}$ toward the tip of the bone marker. For method 2D, the probe tip was shifted $0.75 \mathrm{~mm}$ toward the tip of the bone marker. Registration planning in all cases was performed by the same neurosurgeon to maximally exclude the impact of human factors. Registration errors were recorded for each method. The minimum registration error method was chosen for surgery. Registration and electrode vector errors, intraoperative electrophysiological signal length (IESL), and DBS power-on voltage were recorded. The primary measure of efficacy was the change in the Unified Parkinson's Disease Rating Scale (UPDRS) score and UPDRS Part III (UPDRS-III) score from baseline to 10 weeks after implantation. Before DBS surgery, the patients were tested for UPDRS values in the off-medication state. After DBS surgery, the patients were tested for UPDRS values in the off-medication/on-stimulation state.

\section{Statistical Methods}

The SPSS 19.0 software (IBM Corp.) was used for statistical analysis. In the skull model study, data for methods $1 \mathrm{~A}, 1 \mathrm{~B}$, and $1 \mathrm{C}$ were analyzed using a t-test. In the clinical study, data for methods $2 \mathrm{~A}, 2 \mathrm{~B}, 2 \mathrm{C}$, and $2 \mathrm{D}$ were analyzed using a t-test. For comparing group I and group II in the clinical study, we analyzed registration errors (methods 2E and 2C), postoperative vector errors, electrophysiological signal length, power-on voltage, and UPDRS (UPDRS-III) score improvements by using a t-test. Correlation analysis between registration errors and postoperative electrode vector errors was conducted in both groups. A p value $<0.01$ was significant.

\section{Results}

In the skull model study, the registration error (mean \pm standard deviation) was $0.56 \pm 0.11 \mathrm{~mm}$ for method $1 \mathrm{~A}$, $0.35 \pm 0.11 \mathrm{~mm}$ for method $1 \mathrm{~B}$ (vs. $1 \mathrm{~A}, \mathrm{p}<0.001$ ), and 0.90 $\pm 0.15 \mathrm{~mm}$ for method $1 \mathrm{C}$ (vs. 1A, p < 0.001). Method 1B had the smallest registration error (Table 1).

In the clinical study, basic information for group I was as follows: 16 males, 17 females, mean age $64.7 \pm 9.2$ years, mean disease course $9.4 \pm 2.6$ years. Preoperative scores for UPDRS and UPDRS-III were $61.79 \pm 16.56$ and

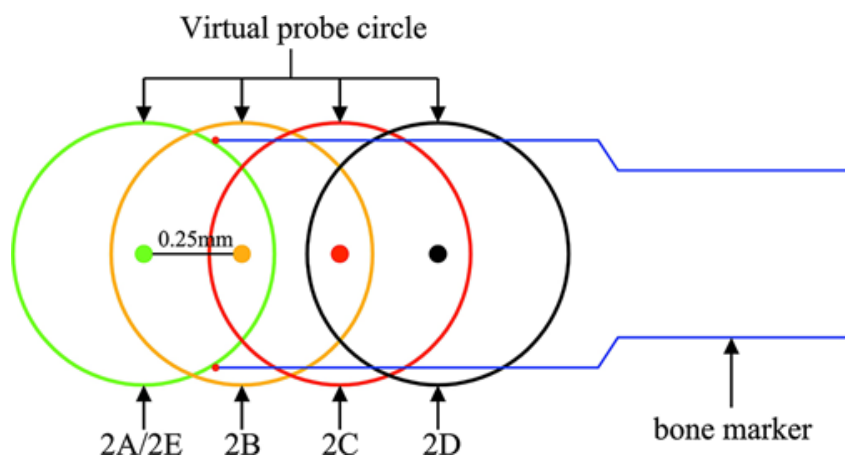

FIG. 2. In the clinical study, patients in group I underwent registration by the conventional method (method 2E) as required by ROSA for the DBS surgery. In group II, patients underwent registration via 4 types of modified methods including $2 \mathrm{~A}, 2 \mathrm{~B}, 2 \mathrm{C}$, and $2 \mathrm{D}$. For method $2 \mathrm{~A}$, the line of the probe tip was set in the groove of the bone markers. For method $2 B$, the probe tip was shifted $0.25 \mathrm{~mm}$ toward the tip of the bone marker. For method $2 \mathrm{C}$, the probe tip was shifted $0.5 \mathrm{~mm}$ toward the tip of the bone marker. For method $2 \mathrm{D}$, the probe tip was shifted $0.75 \mathrm{~mm}$ toward the tip of the bone marker.

$30.00 \pm 8.99$, respectively. A total of 64 electrodes were bilaterally implanted in the STN, and one electrode was unilaterally implanted in the STN. Basic information for group II was as follows: 18 males, 20 females, mean age $65.0 \pm 11.1$ years, mean disease course $9.0 \pm 2.5$ years. Preoperative UPDRS and UPDRS-III scores were 66.32 \pm 20.43 and $29.21 \pm 10.04$, respectively. A total of 74 electrodes were bilaterally implanted in the STN, and one electrode was unilaterally implanted in the STN. There were no significant differences in the basic information between groups I and II.

In the clinical study, method $2 \mathrm{C}$ was chosen for DBS surgery in group II because of its minimal error (Table 1). The mean registration error was $0.62 \pm 0.22 \mathrm{~mm}$ for group I (method 2E, 33 patients) and $0.27 \pm 0.07 \mathrm{~mm}$ for group II (method $2 \mathrm{C}, 38$ patients; $\mathrm{p}<0.001$ ). As shown in Table 2, the postoperative electrode vector error was 0.97 $\pm 0.31 \mathrm{~mm}$ for group I and $0.65 \pm 0.23 \mathrm{~mm}$ for group II $(\mathrm{p}<0.001)$. Group II had a smaller registration error and postoperative electrode vector error. There was a positive correlation between registration error and electrode vector error in both groups (group I: $r=0.69, p<0.001$; group II: $\mathrm{r}=0.71, \mathrm{p}<0.001 ;$ Fig. 3).

TABLE 1. Errors of different registration methods in a skull model and a clinical situation

\begin{tabular}{cccc}
\hline Method & Error Mean \pm SD $(\mathrm{mm})$ & Error Range $(\mathrm{mm})$ & $\mathrm{p} \mathrm{Value}$ \\
\hline $1 \mathrm{~A}$ & $0.56 \pm 0.11$ & $0.42-0.77$ & - \\
\hline $1 \mathrm{~B}$ & $0.35 \pm 0.11$ & $0.23-0.68$ & $<0.001$ (vs 1A) \\
\hline $1 \mathrm{C}$ & $0.90 \pm 0.15$ & $0.64-1.12$ & $<0.001$ (vs 1A) \\
\hline $2 \mathrm{C}$ & $0.27 \pm 0.07$ & $0.11-0.39$ & - \\
\hline $2 \mathrm{~A}$ & $0.61 \pm 0.08$ & $0.47-0.77$ & $<0.001$ (vs 2C) \\
\hline $2 \mathrm{~B}$ & $0.39 \pm 0.12$ & $0.15-0.68$ & $<0.001$ (vs 2C) \\
\hline $2 \mathrm{D}$ & $0.43 \pm 0.11$ & $0.22-0.66$ & $<0.001$ (vs 2C) \\
\hline $2 \mathrm{E}$ & $0.62 \pm 0.22$ & $0.21-0.95$ & $<0.001$ (vs 2C) \\
\hline
\end{tabular}




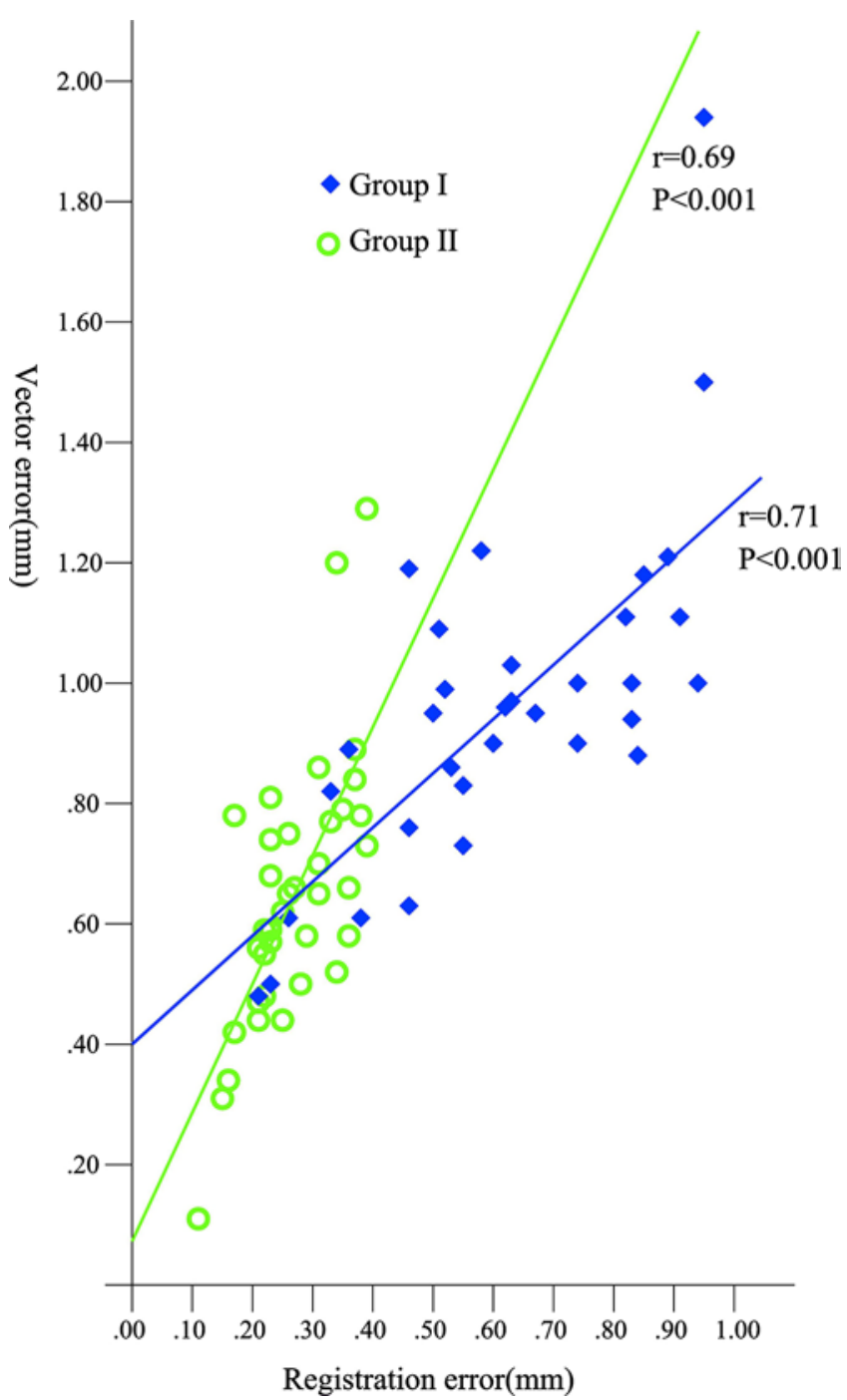

FIG. 3. Errors for all patients were marked. Correlation analysis between registration errors and postoperative electrode vector errors was conducted in both patient groups. There was a positive correlation in both groups (group l: $r=0.69, p<0.001$; group II: $r=0.71, p<0.001$ ).

The mean IESL was $5.0 \pm 0.9 \mathrm{~mm}$ in group I and 5.8 $\pm 0.7 \mathrm{~mm}$ in group II, and the difference between the two was statistically significant $(\mathrm{p}<0.001$; Table 2$)$. The mean DBS power-on voltage was $1.63 \pm 0.44 \mathrm{~V}$ in group I and $1.48 \pm 0.38 \mathrm{~V}$ in group II $(\mathrm{p}=0.027)$. In the UPDRS score, group I showed $50 \% \pm 16 \%$ improvement and group II showed $52 \% \pm 18 \%$ improvement. In the UPDRS-III score, group I showed 52\% $\pm 16 \%$ improvement and group II showed $53 \% \pm 16 \%$ improvement. There was no statistically significant difference in improvement in the UPDRS $(p=0.724)$ or UPDRS-III $(p=0.831)$ scores between the two groups (Table 2).

\section{Discussion}

During the past 3 decades, DBS has become an established treatment for movement disorders and other indications, with more than 120,000 patients worldwide cur-
TABLE 2. DBS-related clinical data for patient groups I and II

\begin{tabular}{lccr}
\hline \multicolumn{1}{c}{ Parameter } & Group I & Group II & p Value \\
\hline No. of patients & 33 & 38 & \\
\hline Registration error $(\mathrm{mm})$ & $0.62 \pm 0.22$ & $0.27 \pm 0.07$ & $<0.001$ \\
\hline $\begin{array}{l}\text { Postop electrode vector error } \\
(\mathrm{mm})\end{array}$ & $0.97 \pm 0.31$ & $0.65 \pm 0.23$ & $<0.001$ \\
\hline IESL $(\mathrm{mm})$ & $5.0 \pm 0.9$ & $5.8 \pm 0.7$ & $<0.001$ \\
\hline Power-on voltage $(\mathrm{V})$ & $1.63 \pm 0.44$ & $1.48 \pm 0.38$ & 0.027 \\
\hline UPDRS improvement $(\%)$ & $50 \pm 16$ & $52 \pm 18$ & 0.724 \\
\hline UPDRS-III improvement (\%) & $52 \pm 16$ & $53 \pm 16$ & 0.831 \\
\hline
\end{tabular}

Values expressed as the mean \pm standard deviation, unless indicated otherwise.

rently implanted with a DBS device. ${ }^{11}$ Precision is considered to be the basic requirement and key factor in DBS..$^{15}$ The STN, a frequent target in DBS surgery, is small and has a deep location..$^{11,16}$ The ability to accurately target and precisely control stimulation can theoretically improve the effectiveness of DBS while avoiding side effects, but given the novelty of this approach, there is no firm clinical evidence. ${ }^{3,4,11,19}$ Electrode implantation for DBS can be performed in numerous ways, but the current gold standard is the use of frame-based systems for accuracy..$^{10}$ Recently, the ROSA device has gained interest. Our team found that the postoperative electrode vector error when assisted by ROSA was $0.68 \pm 0.43 \mathrm{~mm}$ in the $\mathrm{x}$-axis and $0.63 \pm 0.29$ in the $y$-axis in DBS surgery. ${ }^{20}$ In a subsequent study, we found a modified registration method can reduce the errors.

Registration is the first step in ROSA-assisted surgery. ${ }^{16}$ Its purpose is to make a corresponding relationship between the spatial position of the patient's head and 3D data in the ROSA software. The registration error is an indicator of the degree of coincidence between the two data sets. The smaller the registration error is, the higher the coincidence for each point on the head and its corresponding position in ROSA. After registration, the robotic arm can be guided to any site of the head..$^{12}$ In clinical practice, we found that registration errors and the accuracy of electrode implantation may be related. Modified registration in DBS surgery has not been previously reported.

Hence, our team first conducted a skull model test, which showed that the registration error is related to the position of the virtual probe tip in registration. Shifting the probe tip inward can reduce the error, and outward movement can increase the error. However, its suitability for intraoperative registration, the distance of this type of modification for intraoperative registration, and how to achieve a minimum error remain unknown. In this study, our team designed a clinical modified registration test. We found that the error with method $2 \mathrm{C}$ (the probe tip shifted $0.5 \mathrm{~mm}$ toward the tip of the bone marker) was the smallest among all of the registration methods. If the inward modification distance was further increased, the error increased. Data from our clinical study correlated with data from the skull model test. Therefore, registration errors can be modified by adjusting the distance between the probe tip and the bone markers during the registration 
planning process, and there is a relative optimum value for the correction distance.

Our clinical study showed a positive correlation between the registration error and the postoperative electrode vector error in both groups-the smaller the registration error, the smaller the electrode vector error. This indicates that registration error is a key factor in determining the postoperative electrode vector error. Measures can be taken to reduce the registration error to bring the postoperative electrode position closer to the target in order to improve the accuracy of DBS surgery. With the modified registration method with its smaller vector errors, patients had a lower postoperative DBS power-on voltage, which may facilitate a longer DBS battery life. There was no difference between the two groups in the improvements on UPDRS and UPDRS-III scores at 10 weeks after surgery. The long-term effects of the modified registration method need to be further observed and evaluated.

The registration error can be modified, perhaps due to the metal artifact of the bone marker in the CT image. When creating the registration plan, shifting the probe tip $0.5 \mathrm{~mm}$ toward the tip of the bone marker can modify some errors. After using the modified ROSA registration for DBS surgery, we found that the error was smaller than that with conventional registration. The postoperative electrode vector errors with the modified ROSA registration were smaller than those with a frameless system, ${ }^{13}$ the Nexframe head frame system, ${ }^{2}$ and the Leksell head frame system. ${ }^{14}$

Reducing the registration error directly impacts the accuracy of DBS surgery. Registration errors of bone markers result from the discrepancy between the spatial location of the head and its spatial coordinates in the ROSA system. ${ }^{1,18}$ The main sources of registration errors can include the following: 1) error caused by personnel manipulation, 2) image error such as image artifacts of the bone marker, 3) robot system error, and 4) physical factors caused by deformation of the object. ${ }^{8,9}$ In fact, many variables influence the modified distance of the artifact error in the registration plan. Different robots, different bone markers, different CT scanners, different scan parameters, and other factors would affect the modified distance. We have introduced a modified method and evaluated its results. Therefore, neurosurgeons in different hospitals can perform the skull model test to find the optimal modified distance and then apply it to DBS surgery.

\section{Conclusions}

A positive correlation was found between the registration error and the electrode vector error in ROSA-assisted DBS surgery. Our modified registration method could reduce registration errors and electrode vector errors. The results of this study suggested that the modified method can further improve accuracy to about $0.6 \mathrm{~mm}$. With the modified registration method, patients had a smaller postoperative DBS power-on voltage. The UPDRS or UPDRSIII score improvement was similar to that of the conventional registration group at 10 weeks after surgery. The long-term effects of the modified registration method need to be observed and evaluated further.

\section{Acknowledgments}

This study was supported by grants from the National Key Research and Development Program (2016YFC0105904SJT) and the Liaoning Provincial Program of Natural Science (20170540935, 20170520307).

\section{References}

1. Ballesteros-Zebadúa P, García-Garduño OA, Galván de la Cruz OO, Arellano-Reynoso A, Lárraga-Gutiérrez JM, Celis MA: Assessment of an image-guided neurosurgery system using a head phantom. Br J Neurosurg 30:606-610, 2016

2. Bot M, van den Munckhof P, Bakay R, Sierens D, Stebbins G, Verhagen Metman L: Analysis of stereotactic accuracy in patients undergoing deep brain stimulation using Nexframe and the Leksell frame. Stereotact Funct Neurosurg 93:316-325, 2015

3. Dams J, Balzer-Geldsetzer M, Siebert U, Deuschl G, Schuepbach WM, Krack P, et al: Cost-effectiveness of neurostimulation in Parkinson's disease with early motor complications. Mov Disord 31:1183-1191, 2016

4. Krack P, Martinez-Fernandez R, Del Alamo M, Obeso JA: Current applications and limitations of surgical treatments for movement disorders. Mov Disord 32:36-52, 2017

5. Kühn AA, Volkmann J: Innovations in deep brain stimulation methodology. Mov Disord 32:11-19, 2017

6. Lefranc M, Capel C, Pruvot AS, Fichten A, Desenclos C, Toussaint $\mathrm{P}$, et al: The impact of the reference imaging modality, registration method and intraoperative flat-panel computed tomography on the accuracy of the ROSA ${ }^{\circledR}$ stereotactic robot. Stereotact Funct Neurosurg 92:242-250, 2014

7. Lefranc M, Capel C, Pruvot-Occean AS, Fichten A, Desenclos C, Toussaint $P$, et al: Frameless robotic stereotactic biopsies: a consecutive series of 100 cases. J Neurosurg 122:342-352, 2015

8. Li Z, Zhang JG, Ye Y, Li X: Review on factors affecting targeting accuracy of deep brain stimulation electrode implantation between 2001 and 2015. Stereotact Funct Neurosurg 94:351-362, 2016

9. Morishita T, Hilliard JD, Okun MS, Neal D, Nestor KA, Peace D, et al: Postoperative lead migration in deep brain stimulation surgery: incidence, risk factors, and clinical impact. PLoS One 12:e0183711, 2017

10. Pallavaram S, D'Haese PF, Lake W, Konrad PE, Dawant BM, Neimat JS: Fully automated targeting using nonrigid image registration matches accuracy and exceeds precision of best manual approaches to subthalamic deep brain stimulation targeting in Parkinson disease. Neurosurgery 76:756-765, 2015

11. Schüpbach WMM, Chabardes S, Matthies C, Pollo C, Steigerwald F, Timmermann L, et al: Directional leads for deep brain stimulation: opportunities and challenges. Mov Disord 32:1371-1375, 2017

12. Shamir RR, Joskowicz L, Spektor S, Shoshan Y: Localization and registration accuracy in image guided neurosurgery: a clinical study. Int J CARS 4:45-52, 2009

13. Sharma M, Rhiew R, Deogaonkar M, Rezai A, Boulis N: Accuracy and precision of targeting using frameless stereotactic system in deep brain stimulator implantation surgery. Neurol India 62:503-509, 2014

14. Starr PA, Christine CW, Theodosopoulos PV, Lindsey N, Byrd D, Mosley A, et al: Implantation of deep brain stimulators into the subthalamic nucleus: technical approach and magnetic resonance imaging-verified lead locations. J Neurosurg 97:370-387, 2002

15. Steigerwald F, Müller L, Johannes S, Matthies C, Volkmann $\mathrm{J}$ : Directional deep brain stimulation of the subthalamic 
nucleus: a pilot study using a novel neurostimulation device. Mov Disord 31:1240-1243, 2016

16. Vadera S, Chan A, Lo T, Gill A, Morenkova A, Phielipp NM, et al: Frameless stereotactic robot-assisted subthalamic nucleus deep brain stimulation: case report. World Neurosurg 97:762.e11-762.e14, 2017

17. Valsky D, Marmor-Levin O, Deffains M, Eitan R, Blackwell KT, Bergman H, et al: Stop! border ahead: Automatic detection of subthalamic exit during deep brain stimulation surgery. Mov Disord 32:70-79, 2017

18. Wang MN, Song ZJ: Properties of the target registration error for surface matching in neuronavigation. Comput Aided Surg 16:161-169, 2011

19. Wodarg F, Herzog J, Reese R, Falk D, Pinsker MO, Steigerwald F, et al: Stimulation site within the MRI-defined STN predicts postoperative motor outcome. Mov Disord 27:874879, 2012

20. Yang XW, Tao YQ, Jin H, Xu F, Sun X, Wang Y, et al: The accuracy of deep brain stimulation assisted by Robot of Stereotactic Assistant system. Chin J Minim Invasive Neurosurg 22:60-62, 2017

\section{Disclosures}

The authors report no conflict of interest concerning the materials or methods used in this study or the findings specified in this paper.

\section{Author Contributions}

Conception and design: Tao. Acquisition of data: Yang, Sun, Wang, M Xu. Analysis and interpretation of data: F Xu, Yang, Sun, Wang, M Xu. Drafting the article: F Xu, Jin. Critically revising the article: F Xu, Jin. Reviewed submitted version of manuscript: Jin. Statistical analysis: Yang.

\section{Correspondence}

Yingqun Tao: General Hospital of Shenyang Military Area Command, Liaoning, China. yingquntao@163.com. 